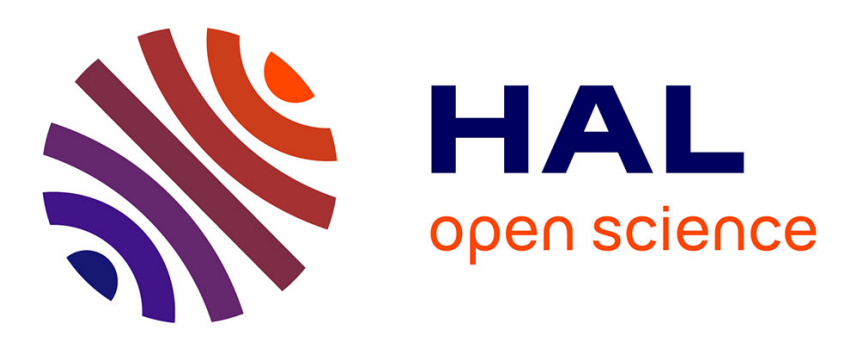

\title{
The Law of One Price: Conditional Convergence Evidence from Disaggregated Data
}

Michael Pfaffermayr

\section{To cite this version:}

Michael Pfaffermayr. The Law of One Price: Conditional Convergence Evidence from Disaggregated Data. Applied Economics, 2009, 41 (26), pp.3345-3357. 10.1080/00036840701426584 . hal-00582067

\section{HAL Id: hal-00582067 https://hal.science/hal-00582067}

Submitted on 1 Apr 2011

HAL is a multi-disciplinary open access archive for the deposit and dissemination of scientific research documents, whether they are published or not. The documents may come from teaching and research institutions in France or abroad, or from public or private research centers.
L'archive ouverte pluridisciplinaire HAL, est destinée au dépôt et à la diffusion de documents scientifiques de niveau recherche, publiés ou non, émanant des établissements d'enseignement et de recherche français ou étrangers, des laboratoires publics ou privés. 


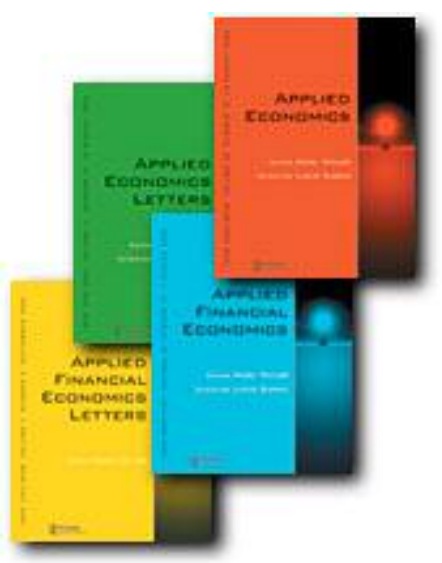

The Law of One Price: Conditional Convergence Evidence from Disaggregated Data

\begin{tabular}{|r|l|}
\hline Journal: & Applied Economics \\
\hline Manuscript ID: & APE-06-0068 \\
\hline Journal Selection: & Applied Economics \\
\hline $\begin{array}{r}\text { Date Submitted by the } \\
\text { Author: }\end{array}$ & 09-Feb-2006 \\
\hline JEL Code: & $\begin{array}{l}\text { F31 - Foreign Exchange < F3 - International Finance }<\text { F - } \\
\text { - Prices, Business Fluctuations, and Cycles < E - Macroeconomics } \\
\text { and Monetary Economics, C21 - Cross-Sectional Models } \mid \text { Spatial } \\
\text { Models < C2 - Econometric Methods: Single Equation Models < C - } \\
\text { Mathematical and Quantitative Methods }\end{array}$ \\
\hline Keywords: & \begin{tabular}{l} 
Purchasing Power Parity, Sigma-Convergence, Beta-Convergence \\
\hline
\end{tabular} \\
\hline
\end{tabular}




\title{
The Law of One Price: Conditional Convergence Evidence from Disaggregated Data
}

\author{
Peter Egger, Stephan Gruber, Michael Pfaffermayr *
}

February 9, 2006

\begin{abstract}
This paper contributes to the literature on the Law of One Price (LOP) and absolute Purchasing Power Parity (PPP) in two ways. First, it uses a novel set of PPP data from the International Comparison Programme for OECD countries and 195 internationally comparable products from 1980 to 1996. Second, it derives and applies a test of conditional $\sigma$-convergence, which does not require long time spans or high frequency data. Between 1990 and 1996 for 10 out of 23 countries a significant reduction in the variance of the deviations from LOP is found for tradeables, but none in case of non-tradeables. For the former, the deviations from LOP close out at half-lives between 2.2 and 6.3 years. However, there are also persistent country-specific deviations from LOP parities.
\end{abstract}

JEL classification: F31, E31, C21

Keywords: Purchasing power parity, $\sigma$-convergence, $\beta$-convergence,

* The authors are very grateful to Statistics Austria, EUROSTAT and, especially, to the OECD for supporting and enabling this project. We would like to thank Mark Nelson and Jeff Bergstrand for valuable comments and suggestions. Address of all three authors: Department of Economics, University of Innsbruck, Universitaetsstrasse 15, A6020 Innsbruck. Corresponding author: Michael Pfaffermayr, Tel.: +43-512-507-7359; Fax: +43-512-507-2980, E-mail: Michael.Pfaffermayr@uibk.ac.at. 


\section{Introduction}

The overwhelming majority of the empirical literature on the Law of One Price (LOP) and Purchasing Power Parity (PPP) is based on time series data of national consumer prices ${ }^{1}$ "That is, because most data take the form of index numbers, most of what we know about LOP and PPP deviations involves the volatility and persistence of changes in relative prices. We know relatively little about the absolute relative prices themselves. This is particularly troublesome given that economic theory places much starker restrictions on absolute LOP deviations than on their changes." (Crucini, Telmer, Zachariadis, 2005, p. 724) $!^{2}$

A considerable part of the empirical LOP research concentrates on individual products. Cumby (1996) studies prices of Big Mac hamburgers, Gosh and Wolf (1994) investigate the price of The Economist magazine, Haskel and Wolf (2001) look at the prices of IKEA furniture, Froot, Kim and Rogoff (2001) concentrate on basic commodities like wheat, butter and charcoal, and Lutz (2001) assesses automobile prices.$^{3}$ Most of the available LOP-studies use price data of cities in North America or the European Union. Only recently, serious efforts have been undertaken to reinvestigate LOP consider-

\footnotetext{
${ }^{1}$ The Law of One Price (LOP) states that identical goods sold in different countries and/or locations should exhibit the same price expressed in common currency units, while Purchasing Power Parity (PPP) implies that similar baskets of goods should be identically priced once expressed in common units.

${ }^{2}$ In particular, the analysis of changes in relative prices (relative PPP) is not sufficient to show that international price differences cancel out over time in levels (absolute PPP). Here, we concentrate on LOP, i.e. absolute PPP. Recent contributions to relative PPP literature are Rogoff (1996), O'Connel (1998a, 1998b), Cheung and Lai (2000a, 2000b), Higgins and Zakrajsek (2000), Baum, Barkoulas and Caglayan (2001), Taylor and Peel (2000), Taylor (2001, 2002), Murray and Pappell (2002), Taylor and Taylor (2004).

${ }^{3}$ See also Isard (1977), Giovannini (1988), and Knetter $(1989,1993)$ for early but influential contributions.
} 
ing larger cross-sections of goods as well as countries. Well-known examples are Crownover, Pippenger and Steigerwald (1996), Engel and Rogers (1996), Parsley and Wei (1996, 2001, 2004), Crucini, Telmer and Zachariadis (2000, 2005), Cecchetti, Mark and Sonora (2000), Rogers (2001), O’Connel and Wei (2002), Lutz (2002), Crucini and Shintani (2004), or Goldberg and Verboven (2005).

Recent research in the field is characterized by (i) the use of micro-level data and (ii) the application of dynamic panel econometric methods and/or panel unit root tests. While there is consensus that prices in fact deviate widely and quite persistently from LOP, especially across countries, there remains considerable variation in the estimated half-lives and the assessment of the adjustment dynamics towards LOP parities.

This paper stresses two essential aspects, which seem not to be dealt with sufficiently in the literature. The first one relates to the data in use, and the second one to the assumption about the data generating process of $\mathrm{LOP} / \mathrm{PPP}$ data.

First, for the comparability of goods prices (measured in the same currency) across countries, and maybe even within countries, it is essential to rely on homogeneously specified, quality adjusted goods or aggregates thereof. Relating to LOP studies at the aggregate level, Obstfeld and Rogoff (1996, p.202) assert that "The best evidence we have on absolute PPP comes from the Penn World Table(PWT), the culmination of a sequence of studies, starting with Gilbert and Kravis (1954), and described more recently by Summers and Heston (1991). The PWT endeavors to compare, in levels, the US dollar prices of identical, quality adjusted output baskets for a large 
sample of countries." Building on the pioneering work of Gilbert, Kravis, Summers and Heston, the International Comparison Programme (ICP) collects a wide range of goods prices in each participating country with great effort. ICP is a very comprehensive and advanced statistical exercise, coordinated by the United Nations Statistical Department and conducted with support of national statistical agencies, EUROSTAT, and the OECD at a three to five years frequency (also Bergstrand, 1991, 1992, recommends the use of ICP data). This paper represents a first attempt to exploit the ICP data for OECD countries at the disaggregated level of 195 internationally comparable products (basic headings) to study deviations from LOP.

Second, by relying on dynamic panel data methods and panel unit root tests, recent research on PPP implicitly assumes that the data generating process of prices in common currency already runs for an infinite number of periods. Although this is a possible working hypothesis, political shocks such as World War II or the oil crises in the late 70s and early 80s may represent distortions, which are at odds with this assumption. Following Hart (1995), we argue that looking at $\beta$-convergence, i.e., the absence of a unit root, is not sufficient to detect $\sigma$-convergence so that the distribution of real exchange rates indeed collapses over time. We may observe a rising variance (i.e., no $\sigma$-convergence), in spite of $\beta$-convergence. This is the case if the variance in the initial period is above its long run steady state level as implied by the corresponding stationary $\mathrm{AR}(1)$-process and if the variance of the innovations is large, too. Hence, in this likely relevant case we need a test of $\sigma$-convergence in addition to estimates of the $\beta$-convergence coefficient. Only if the null of no $\sigma$-convergence is rejected, the half-lives based on the 
$\beta$-convergence coefficient can be interpreted sensibly.

Since our ICP data form a large cross-section (195 products in 23 countries), but exhibit a small time dimension (only 5 observations between 1980 and 1996 are available), we look at both $\beta$ - and $\sigma$-convergence over a given period of time without relying on large $T$ asymptotics as unit root tests do. Accordingly, we test whether the variance of the real exchange rate has declined over time (see Hart, 1995). To accomplish this task, we design and apply a likelihood ratio test of conditional $\sigma$-convergence. This test is a generalization of the test of unconditional $\sigma$-convergence by Carree and Klomp (1997) In addition, we estimate the associated speed of adjustment from the $\beta$-convergence regressions.

Summing up the main results, the ICP data provide clear evidence that international goods prices expressed in common currency units deviate remarkably from LOP parities at any considered period. Concerning $\sigma$-convergence we find that over the period 1990-1996 10 out of 23 countries experienced a significant reduction in the variance of the deviations from LOP for tradeable goods, but no reduction in case of non-tradeables. For the longer period between 1980 and 199610 out of 16 countries show a significant decrease of the variance of LOP deviations for tradeable goods. The corresponding $\beta$-convergence estimates exhibit half-lives for LOP deviations of between 3.4 and 8.1 years over the period 1990-1996, while the adjustment towards parity occurs faster (2.2 to 6.3 years) for tradeable goods at competitive markets. Over the longer period, our half-live estimates are somewhat bigger, hence, conditional convergence is slower.

\footnotetext{
${ }^{4}$ In Egger and Pfaffermayr (2006) an even more general Wald-test on conditional $\sigma$ convergence is provided. As long as all explanatory variables are dummy variables as in our application, the here derived LR-test on conditional $\sigma$-convergence is sufficient.
} 


\section{The database}

In contrast to national Consumer Price Index (CPI) data, the ICP price information exhibits a few very desirable properties (see United Nations, 1992):

First, the ICP methodology provides a very detailed description of goods and services for which price data have to be collected. The list of items to be included in the international basket of goods consists of identical specifications throughout all countries participating in the comparison. Furthermore, the ICP framework has elaborated careful instructions for statistical agencies concerning where, what, and when prices have to be monitored in each country. National statistical agencies are prompted to report only prices of goods, which are representative for the local market.

Second, ICP provides price information on a wide range of products at a very detailed level of disaggregation. PPPs are calculated for each homogeneous category of goods and services, the so-called "basic headings". Close inspection of the list of basic headings allows to separate tradeable goods from non-tradeable local goods and services. There are 195 basic headings, each consisting of 5 to more than 50 goods and services uniformly specified for all participating countries.$^{5}$

Third, PPPs are computed for each basic heading, reference country are the US. No explicit weights are applied to each of the items within a basic heading for calculation of PPPs at the basic heading level $(p)$. Special computational methods (Eltetö-Köves-Szulc (EKS) method; see Drechsler, 1973)

\footnotetext{
${ }^{5}$ The final list of products narrowly specified for the 1996 OECD/EUROSTAT comparison covers over 2900 consumer goods and services, 34 occupations in government, education and health services, 186 equipment goods and 20 construction projects.
} 
are used to obtain transitive parities throughout the whole set of participating countries. At the level of basic headings, parities are therefore invariant to the choice of the base country. Since ICP data provide homogeneous baskets of goods throughout all comparison countries, tests for absolute PPP in levels rather than relative PPP in growth rates are possible.

The OECD provided the authors with the PPP-data at the basic heading level covering the comparison rounds 1980, 1985, 1990, 1993 and 1996 for 24 OECD countries from the joint OECD/EUROSTAT PPP Programme ${ }^{6}$

Official annual average US-Dollar nominal exchange rates $(s)$ published by the International Monetary Fund have been used to calculate real exchange rates $(r)$ for each price observation and each comparison year $(t)$. Real exchange rates at the basic heading level are defined as: $r_{c i t}=s_{c t}+p_{c i t}-p_{U \text { Sit }}$, where all variables are in $\operatorname{logs}, c$ denotes the country index and $i$ is the basic heading index.

Furthermore we have constructed a dummy variable to classify each basic heading as a "tradeable" (tr) or "non-tradeable" (ntr) good. Those basic headings that are tradeable in principle, but not traded at competitive market prices (e.g., town gas, books, etc.) have been classified as non-tradeable. Details about this classification and the data set are available from the authors upon request.

\footnotetext{
${ }^{6}$ The country sample consists of Germany, France, Italy, Netherlands, Belgium, Luxembourg, United Kingdom, Ireland, Denmark, Greece, Spain, Portugal, Austria, Switzerland, Finland, Iceland, Norway, Sweden, Turkey, Australia, New Zealand, Japan, Canada, USA. Note, due to small changes in the classification, a few basic headings are not available in all of the rounds.
} 


\section{Measuring conditional convergence}

The time series dimension of the panel data set consists of three to five observations over time for each country and basic heading. So we are faced with a fat panel with $N$ large and $T$ small, and panel unit root tests are not applicable in the present context. Furthermore, if the data generating process exhibits fixed starting values, the absence of a unit root is not sufficient to detect convergence in the sense that the distribution of relative prices collapses in the course of time. As Hart (1995) illustrates, it may well be that relative prices are stationary and follow an $\mathrm{AR}(1)$ process. However, their variance only shrinks over time (i) if the initial variance is sufficiently large, (ii) there is $\beta$-convergence and (iii) the yearly innovations exhibit a low enough variance. Therefore, it is possible to observe a constant variance along with $\beta$-convergence. In short, in order to detect convergence in the sense of a collapsing (unimodal) distribution, $\beta$-convergence is necessary but not sufficient (see also Barro and Sala-i-Martin, 2003). To see this, define $\pi=1+b$ and write the $\beta$-convergence equation as (ignoring the constant, the dummies and the index for countries and basic headings for the moment):

$$
y_{T}=(1+b)^{T-1} y_{1}+\sum_{t=2}^{T}(1+b)^{T-t} \nu_{t}=\pi y_{1}+u_{T}
$$

so that

$$
\sigma_{T}^{2}=\pi^{2} \sigma_{1}^{2}+\sigma_{u T}^{2}
$$

We assume that $\nu$ is $i i d N\left(0, \sigma_{\nu}^{2}\right)$ so that $u_{T}$ is also $i i d$ normal with variance $\sigma_{u T}^{2}$ and $y_{1} \sim$ iid $N\left(0, \sigma_{y_{1}}^{2}\right)$. Hence, for fixed $T$ we have a unique mapping of the time series model into the cross-sectional model. From (2) it can immediately be seen that we observe $\sigma$-convergence between periods 1 and 
$T$, if $\sigma_{T}<\sigma_{1}$ or $\pi^{2}<\pi_{0}^{2}=\frac{\sigma_{1}^{2}-\sigma_{u}^{2}}{\sigma_{1}^{2}}$. The latter term $\left(\pi_{0}\right)$ is always lower than 1 , if $\sigma$-convergence takes place and the process starts at a variance higher than the long run steady state value.7 Therefore, finding $\beta$-convergence with $\pi<1$ is necessary but not sufficient for $\sigma$-convergence, since under $\pi_{0}<\pi<1$ the variance of $y$ actually increases. In the Appendix, we propose a likelihood ratio test to test this hypothesis. This test is based on the work of Carree and Klomp (1997) and Egger and Pfaffermayr (2006), and allows for conditional convergence by introducing additional dummies. Specifically, we test the hypothesis $H_{0}: \sigma_{T}^{2}=\sigma_{1}^{2}$ vs. $H_{1}: \sigma_{T}^{2}<\sigma_{1}^{2}$. We estimate the $\beta$-convergence regressions first for each country separately and then for groups of countries. The country-specific specification is given by

$$
r_{c i T}=\alpha_{c}+\beta_{c} r_{c i 1}+\mu_{1 c} d_{i}+\mu_{2 c} d_{i} r_{c i 1}+\varepsilon_{c i T}
$$

where $r_{c i t}, t=1, T$ denotes the real exchange rate of country $c$ and basic heading $i$ in period $t . d_{i}$ is our dummy variable for the tradeability of goods. The interaction term $d_{i} r_{c i 1}$ captures a possible difference in the speed of convergence between these two groups of goods. Lastly, a constant which is different from zero indicates permanent LOP deviations. The implied halflives can be easily estimated by $t_{i 0.5}=-T \ln (2) / \ln \left(1+\beta_{c}+\mu_{2 c}\right)$.

The second specification pools over country groups. It introduces countryspecific effects, which capture location-specific determinants of the deviations from LOP.

$$
r_{c i T}=\alpha_{c}+\beta r_{c i 1}+\mu_{1} d_{i}+\mu_{2} d_{i} r_{c i 1}+\varepsilon_{c i T}
$$

In both cases, we assume that the starting value is independent of the

\footnotetext{
${ }^{7}$ For $T$ approaching infinity we have $\sigma_{T} \rightarrow \frac{\sigma_{\nu}}{-2 b-b^{2}}$ for $b<0$, so that we observe $\sigma$-convergence if $\sigma_{1}^{2}>\frac{\sigma_{\nu}}{-2 b-b^{2}}$.
} 
error in period $t>1$ so that $r_{c i 1}$ is exogenous. In case of an $\operatorname{AR}(1)$ process in annual time intervals $\sigma_{u}$ comprises the error terms from period $T$ to 2 , while the initial value has date 1.8 Hence, if the underlying $\operatorname{AR}(1)$-process exhibits white noise errors, exogeneity of $r_{c i 1}$ is guaranteed.

At the country level we look at $\sigma$-convergence for tradeables and nontradeables separately, so the test is on convergence to the corresponding steady states. The test for country aggregates is on conditional $\sigma$-convergence, i.e it allows for conditioning on exogenous dummy-variables. In both cases, the test is a likelihood ratio test. We show in the Appendix, that the corresponding test statistic is easy to calculate and it is distributed as $\chi_{2}(1)$.

$$
L R=-2\left(L_{1}-L_{0}\right)=N K \ln \left[\frac{\widehat{\sigma}_{1,0}^{2} \widehat{\sigma}_{u, 0}^{2}}{\widehat{\sigma}_{1}^{2} \widehat{\sigma}_{u}^{2}}\right] .
$$

The estimators of the variances under $H_{0}, \widehat{\sigma}_{1,0}^{2}$ and $\widehat{\sigma}_{u, 0}^{2}$, as well as those under $H_{1}, \widehat{\sigma}_{1}^{2}$ and $\widehat{\sigma}_{u}^{2}$, are defined in the Appendix.

\section{Estimation results}

A first inspection of the ICP data reveals undoubted evidence for the fact that real exchange rates implied by disaggregated international goods prices deviate widely from LOP parities. Table 1 shows the (unweighted) mean values of PPPs over all goods (basic headings) for each country and ICP comparison round. The mean parities indicate sound LOP deviations. Given that the US-dollar is used as the reference currency, the descriptive statistics point to a substantially overvalued Dollar for the most observations in our sample.

\footnotetext{
${ }^{8}$ If there is an infinite history of the process with a switch in the variance at period 1 , the MA-representation implies that the starting value includes all previous errors up to period 1.
} 
The evidence on $\sigma$-convergence is summarized in Tables 2-4. Between 1990 and 1996, there is $\sigma$-convergence in 10 countries in case of tradable goods, but none in case of non-tradeables. Specifically, the integration process in the 90s seems to have induced convergence in prices in Europe. In the long period 1980 to 1996, a significant reduction of the variance of LOP deviations occurs in 9 out of 16 countries for tradeable goods. For 7 countries the $H_{0}$ of no $\sigma$-convergence is rejected also for the non-tradeables. For all countries together as well as for the EU12-countries and the EFTA-economies the test likewise rejects for both groups of goods for the longer period 1980-1996 as well as for the period 1990-1996. Hence, one can conclude that there is some tendency of convergence in absolute prices, particularly in the case of tradeables.

The findings concerning $\sigma$-convergence merit a closer look at the $\beta$ convergence regressions. Tables 5-7 report the country-specific estimates. Generally, we observe much bigger half-lives for non-tradeables lasting between 3.4 and 8.1 years for the period 1990-1996, while for tradeables these figures are between 2.2 and 6.3 years. For the longer period 1980-1996 the estimates for the half-lives are relatively bigger. To some extent, this indicates that new shocks have occurred within this longer period. The slower convergence in the 80s may be an additional reason for this finding (see Table 5). The importance of country-specific intercepts is underlined by the corresponding t-tests of the constant and the tradeability dummy. In case of non-tradeable goods, these are significant for 16 out of 23 countries over the period 1990-1996. More surprisingly, there are also 10 countries where significant intercepts are found for the group of tradeable goods. The corresponding 
estimates for the country groups in Table 8-10 confirm these findings. Over the period 1990-1996 the half-live of the pooled estimation over all countries is 4.0 years for tradeable goods and 5.6 years for non-tradeables, respectively. Again the corresponding figures for the period 1980-1996 are higher.

For the interpretation of these findings, one has to bear in mind that we allowed for country-specific intercepts (i.e., country-specific deviations from LOP). These persistent deviations are in sharp contrast with the theoretical propositions behind LOP and absolute PPP. Yet they are significant in many empirical LOP-studies 9 Obviously, country-specific influences such as national tax law and transportation costs may cause permanent differences in international relative price levels, which can not be arbitraged away easily by international goods trade. 10 Our econometric estimates illustrate that it is important to control for these country-specific influences.

\section{Conclusions}

This paper uses disaggregated price data collected within the framework of the International Comparison Programme (ICP), which provides a very comprehensive and advanced statistical database on a large set of internationally

\footnotetext{
${ }^{9}$ See Crucini and Shintani (2004, p.16): "In any case it seems fair to say that the absolute convergence hypothesis is flagrantly violated across international cities and at best weakly supported by the U.S. data. ... Our results using absolute price data indicate that the resting point of most Law-of-One-Price deviations is not zero as implied by the theoretical proposition, even across cities within countries."

${ }^{10}$ Engel and Rogers (1996, p.1114) mention several reasons as to why deviations from absolute PPP might occur: (i) geographically segmented markets combined with market power (ii) productivity differences, (iii) differences in prices of non-tradeable inputs due to wage differences and (iv) price differences of tradeable intermediates due to trade barriers. If a good is principally tradeable, the degree of trade barriers limits possible arbitrage and defines the width of the possible deviations from PPP. Parsley and Wei (1996) provide evidence for US cities that the lack of tradeability of goods and services is sufficient to drive a permanent wedge between prices at different locations even within the same country (see also O'Connel and Wei, 2002).
} 
comparable goods prices. For the OECD countries, price comparisons have been conducted every three to five years. As a result, a panel with a large cross-section, but a very small time dimension is available to compare price levels across countries even at the disaggregated level. In particular, we are able to distinguish between tradeable and non-tradeable goods.

We propose a new test of conditional $\sigma$-convergence for fixed and even small $T$ based on Carree and Klomp (1997). Rejecting a unit root in a time series or, for fixed $T$, finding $\beta$-convergence in a cross-section is not sufficient to detect $\sigma$-convergence. For a sufficiently high - but lower than unity correlation between initial and end year values the variances of price levels might still be growing over time.

Our estimation results indicate that significant $\sigma$-convergence took place in the majority of OECD countries, specifically for tradeable goods, once it is controlled for permanent and country-specific deviations from the law of one price. In line with other studies these turn out to be significant and reflect variables such as trade and transportation costs, differences in taxes and other influences, which all warrant further investigation. Overall, one can conclude that the distribution of relative prices at an international level tends to shrink over time and there is some tendency of convergence. In line with previous findings the corresponding half-lives of LOP deviations to close out over time turn out to be much higher for non-tradeables than for tradeables. 


\section{Appendix: A LR-Test on Conditional $\sigma$-Convergence}

(i) Similar to Carree and Klomp (1997), we formulate the convergence equation by the autoregressive process for fixed $T$, by substituting $T$ periods backwards to get

$$
y_{i k T}=\pi y_{i k 1}+\mu_{k}+u_{i k T}
$$

where $\mu_{k}$ are fixed effects (in our case referring to groups of basic headings) and $u_{i k T}$ is iid $N\left(0, \sigma_{u}^{2}\right)$. In contrast to Carree and Klomp, in this specification we control for heterogeneity and allow for conditional convergence with $K$-specific steady states. The starting values $y_{i k 1}$ are supposed to be iid $N\left(\mu_{k 1}, \sigma_{1}^{2}\right)$ with $\mu_{k 1} \neq \mu_{k}$ and $E\left[y_{i k 1} u_{i k T}\right]=0$ 11 Based on (6), under the null hypothesis of no $\sigma$-convergence we set $\sigma_{T}^{2}=E\left[\left(y_{i k T}-\pi \mu_{k 1}-\mu_{k}\right)^{2}\right]$ $=E\left[\left(\pi\left(y_{i k 1}-\mu_{k 1}\right)+u_{i k T}\right)^{2}\right]=\pi^{2} \sigma_{1}^{2}+\sigma_{u}^{2}$ equal to $\sigma_{1}^{2}$. Hence, we test $H_{0}$ : $\pi^{2}=\pi_{0}^{2}<1-\frac{\sigma_{u}^{2}}{\sigma_{1}^{2}}$ vs. $H_{1}: \pi<\pi_{0}$. This test is based on the bivariate normal distribution (see Cannon and Duck, 2000; Carree and Klomp, 1997; or Egger and Pfaffermayr, 2006):

$$
\left[\begin{array}{c}
y_{i k 1} \\
y_{i k T}
\end{array}\right] \sim N\left(\left[\begin{array}{c}
\mu_{k 1} \\
\pi \mu_{k 1}+\mu_{k}
\end{array}\right],\left[\begin{array}{cc}
\sigma_{1}^{2} & \pi \sigma_{1}^{2} \\
\pi \sigma_{1}^{2} & \pi^{2} \sigma_{1}^{2}+\sigma_{u}^{2}
\end{array}\right]\right)
$$

using $E\left[\left(y_{i k T}-\pi y_{i k 1}-\mu_{k}\right)\left(y_{i k 1}-\mu_{k 1}\right)\right]=E\left[\left(\pi\left(y_{i k 1}-\mu_{k 1}\right)+u_{i k T}\right)\left(y_{i k 1}-\mu_{k 1}\right)\right]$ $=\pi \sigma_{1}^{2}$.

(ii) The likelihood under $H_{1}$ is given by

$$
L_{1}=-\frac{N K}{2}\left(\ln \left(4 \Pi^{2}\right)+\ln \left(\sigma_{1}^{2} \sigma_{u}^{2}\right)+\frac{S}{N K}\right) \text { with }
$$

\footnotetext{
${ }^{11}$ This assumption guarantees that, in contrast to the dynamic fixed effects model (Anderson and Hsiao, 1982; Hsiao, 2003), our estimate is consistent and unbiased. Note that the assumption of differing group effects can principally be tested for.
} 


$$
\begin{aligned}
S= & \frac{1}{\sigma_{1}^{2} \sigma_{u}^{2}} \sum_{k=1}^{K} \sum_{i=1}^{N}\left[\begin{array}{cc}
y_{i k 1}-\mu_{k 1} & y_{i k T}-\pi y_{i k 1}-\mu_{k}
\end{array}\right] \\
& {\left[\begin{array}{cc}
\pi^{2} \sigma_{1}^{2}+\sigma_{u}^{2} & -\pi \sigma_{1}^{2} \\
-\pi \sigma_{1}^{2} & \sigma_{1}^{2}
\end{array}\right]\left[\begin{array}{c}
y_{i k 1}-\mu_{k 1} \\
y_{i k T}-\pi y_{i k 1}-\mu_{k 1}
\end{array}\right] } \\
= & \sum_{k=1}^{K} \sum_{i=1}^{N}\left(\frac{\left(y_{i k T}-\pi y_{i k 1}-\mu_{k}\right)^{2}}{\sigma_{u}^{2}}+\frac{\left(y_{i k 1}-\mu_{k 1}\right)^{2}}{\sigma_{1}^{2}}\right) .
\end{aligned}
$$

The first order conditions are as follows:

$$
\begin{aligned}
& \frac{\partial L_{1}}{\partial \mu_{k 1}}=\frac{1}{2} \sum_{i=1}^{N} \frac{2\left(y_{i 1}-\widehat{\mu}_{k 1}\right)}{\sigma_{1}^{2}}=0 \Rightarrow \widehat{\mu}_{k 1}=m_{1}\left(\mathbf{y}_{1 k}\right), \\
& \frac{\partial L_{1}}{\partial \mu_{k}}=\frac{1}{2} \sum_{i=1}^{N} \frac{2\left(y_{i k T}-\widehat{\pi} y_{i k 1}-\widehat{\mu}_{k}\right)}{\sigma_{u}^{2}}=0, \\
& \frac{\partial L_{1}}{\partial \pi}=\frac{1}{2} \sum_{i=1}^{K} \sum_{i=1}^{N} \frac{2\left(y_{i k T}-\widehat{\pi} y_{i k 1}-\widehat{\mu}_{k}\right)}{\sigma_{u}^{2}} y_{i k 1}=0,
\end{aligned}
$$

where $m_{1}\left(\mathbf{y}_{k 1}\right)$ denotes the group-specific first moments. Defining the $(N K \times$ $K)$ dummy variables matrix $\mathbf{D}$ and $\mathbf{Q}=\left(I_{N K}-\mathbf{D}\left(\mathbf{D}^{\prime} \mathbf{D}\right)^{-1} \mathbf{D}^{\prime}\right), \mathbf{Q y}_{T}$ and $\mathbf{Q y}_{1}$ have typical elements $\widetilde{y}_{i k T}=y_{i k T}-m_{1}\left(\mathbf{y}_{k T}\right)$ and $\widetilde{y}_{i k 1}=y_{i k 1}-m_{1}\left(\mathbf{y}_{k 1}\right)$ (Fuller and Battese, 1973). Therefore, $\widehat{\pi}=\frac{\sum_{i=1}^{K} \sum_{i=1}^{N} \widetilde{\widetilde{i}}_{i k T} \widetilde{y}_{i k 1}}{\sum_{i=1}^{K} \sum_{i=1}^{N}\left(\widetilde{y}_{i k 1}\right)^{2}}=\frac{c\left(\widetilde{\mathbf{y}}_{1} \widetilde{\mathbf{y}}_{T}\right)}{c\left(\widetilde{\mathbf{y}}_{1}\right)}$, $\widehat{\mu}_{k}=m_{1}\left(\mathbf{y}_{k T}\right)-\widehat{\pi} m_{1}\left(\mathbf{y}_{k 1}\right)$, where $c($.$) denotes the second central moment.$ Furthermore,

$$
\begin{aligned}
& \frac{\partial L_{1}}{\partial \sigma_{1}^{2}}=-\frac{N K}{2} \frac{1}{\sigma_{1}^{2} \sigma_{u}^{2}}+\frac{1}{2} \frac{\sum_{k=1}^{K} \sum_{i=1}^{N}\left(y_{i k 1}-\mu_{k 1}\right)^{2}}{\sigma_{1}^{4}} \Rightarrow-\frac{N K}{2} \widehat{\sigma}_{1}^{2} \widehat{\sigma}_{u}^{4}-\frac{N}{2} \widehat{\sigma}_{u}^{4} \sum_{k=1}^{K} c\left(\mathbf{y}_{k 1}\right)= \\
& 0 \Rightarrow \widehat{\sigma}_{1}^{2}=\bar{c}\left(\mathbf{y}_{1}\right), \\
& \frac{\partial L_{1}}{\partial \sigma_{u}^{2}}=-\frac{N K}{2} \frac{\sigma_{1}^{2}}{\sigma_{1}^{2} \sigma_{u}^{2}}+\frac{1}{2} \frac{\sum_{k=1}^{K} \sum_{i=1}^{N}\left(y_{i k T}-\pi y_{i k 1}-\mu_{k}\right)^{2}}{\sigma_{u}^{4}} \Rightarrow-\frac{N K}{2} \widehat{\sigma}_{1}^{4} \widehat{\sigma}_{u}^{1}-\frac{N K}{2} \bar{c}(\mathbf{u}) \widehat{\sigma}_{u}^{4}=0 \\
& \Rightarrow \widehat{\sigma}_{u}^{2}=\bar{c}(\mathbf{u}),
\end{aligned}
$$

where $\bar{c}\left(\mathbf{y}_{1}\right)=\frac{1}{K} \sum_{k=1}^{K} c\left(\mathbf{y}_{k 1}\right) \cdot \bar{c}(\mathbf{u})$ is analogously defined. Inserting into the likelihood gives

$$
L_{1}=-\frac{N K}{2}\left(\ln \left(4 \Pi^{2}\right)+\ln \left(\widehat{\sigma}_{1}^{2} \widehat{\sigma}_{u}^{2}\right)+2\right) .
$$

(iii) Under $H_{0}$, one has to maximize the restricted likelihood function

$$
\left.L_{0}=-\frac{N K}{2}\left(\ln \left(4 \Pi^{2}\right)+\ln \right\urcorner\left(\sigma_{1}^{2} \sigma_{u}^{2}\right)+\frac{S_{R}}{N K}\right) \text { with }
$$




$$
S_{R}=\sum_{k=1}^{K} \sum_{i=1}^{N}\left(\frac{\left(y_{i k T}-y_{i k 1} \sqrt{\left(\sigma_{1}^{2}-\sigma_{u}^{2}\right) / \sigma_{1}^{2}}-\mu_{k}\right)^{2}}{\sigma_{u}^{2}}+\frac{\left(y_{i k 1}-\mu_{k 1}\right)^{2}}{\sigma_{1}^{2}}\right)
$$

The corresponding first order conditions read as follows:

$$
\begin{aligned}
& \frac{\partial L_{0}}{\partial \mu_{k 1}}=\frac{1}{2} \sum_{i=1}^{N} \frac{2\left(y_{i k 1}-\widehat{\mu}_{k 1}\right)}{\sigma_{1}^{2}}=0 \Rightarrow \widehat{\mu}_{k 1,0}=m_{1}\left(\mathbf{y}_{k 1}\right), \\
& \frac{\partial L_{0}}{\partial \mu_{k}}=\frac{1}{2} \sum_{i=1}^{N} \frac{2\left(y_{i k T}-y_{i k 1} \sqrt{\left(\widehat{\sigma}_{1,0}^{2}-\widehat{\sigma}_{u, 0}^{2}\right) / \widehat{\sigma}_{1,0}^{2}}-\widehat{\mu}_{k, 0}\right)}{\sigma_{u}^{2}}=0 \Rightarrow \widehat{\mu}_{k, 0}=m_{1}\left(\mathbf{y}_{k T}\right)-\widehat{\pi}_{0} m_{1}\left(\mathbf{y}_{1 k}\right) .
\end{aligned}
$$

Now define $\widetilde{y}_{i k T}=y_{i k T}-\widehat{\mu}_{k, 0}$ and insert for $\widehat{\mu}_{k, 0}$ :

$\frac{\partial L_{0}}{\partial \sigma_{1}^{2}}=-\frac{N K}{2} \frac{\sigma_{u}^{2}}{\sigma_{1}^{2} \sigma_{u}^{2}}-\frac{1}{2} \sum_{k=1}^{K} \sum_{i=1}^{N} \frac{1}{\sigma_{u}^{2}}\left(-\left(\frac{\sigma_{1}^{2}-\sigma_{u}^{2}}{\sigma_{1}^{2}}\right)^{-\frac{1}{2}}\left(\frac{\sigma_{u}^{2}}{\sigma_{1}^{4}}\right) y_{i k 1} \widetilde{y}_{i k T}+\frac{2 \mu_{k 1} y_{i k 1}}{\sigma_{1}^{4}}-\frac{\mu_{k 1}^{2}}{\sigma_{1}^{4}}\right)$.

$\widehat{\sigma}_{1,0}^{2}=\frac{1}{K} \sum_{k=1}^{K}\left(\frac{1}{\widehat{\pi}_{0}}\left(m\left(\mathbf{y}_{k 1}, \mathbf{y}_{k T}\right)-m_{1}\left(\mathbf{y}_{k 1}\right) m_{1}\left(\mathbf{y}_{k T}\right)+\widehat{\pi}_{0} m_{1}\left(\mathbf{y}_{k 1}\right)^{2}\right)-m_{1}\left(\mathbf{y}_{k 1}\right)^{2}\right)=$ $\sum_{k=1}^{K} \frac{1}{\widehat{\pi}_{0}} c\left(\mathbf{y}_{1 k}, \mathbf{y}_{T k}\right)=\frac{1}{\widehat{\pi}_{0}} \bar{c}\left(\mathbf{y}_{1}, \mathbf{y}_{T}\right)$.

$\frac{\partial L_{0}}{\partial \sigma_{u}^{2}}=-\frac{N K}{2} \frac{\sigma_{1}^{2}}{\sigma_{1}^{2} \sigma_{u}^{2}}-\frac{1}{2} \sum_{k=1}^{K} \sum_{i=1}^{N}\left(-\frac{\widetilde{y}_{i k T}^{2}}{\sigma_{u}^{4}}+\left(\frac{\sigma_{1}^{2}-\sigma_{u}^{2}}{\sigma_{1}^{2} \sigma_{u}^{4}}\right)^{-\frac{1}{2}}\left(\frac{1}{\sigma_{1}^{2}} \frac{-\sigma_{u}^{4}-\left(\sigma_{1}^{2}-\sigma_{u}^{2}\right) 2 \sigma_{u}^{2}}{\sigma_{u}^{6}}\right) y_{i k 1} \widetilde{y}_{i k T}\right.$

$\left.-\frac{y_{i k 1}^{2}}{\sigma_{u}^{4}}\right)=-N K \sigma_{u}^{2}+\sum_{k=1}^{K} \sum_{i=1}^{N}\left(\left(y_{i k T}-\widehat{\mu}_{k}\right)^{2}-\left(\frac{\sigma_{1}^{2}-\sigma_{u}^{2}}{\sigma_{1}^{2} \sigma_{u}^{4}}\right)^{-\frac{1}{2}}\left(\frac{2 \sigma_{1}^{2}-\sigma_{u}^{2}}{\sigma_{1}^{2} \sigma_{u}^{2}}\right) y_{i k 1}\left(y_{i k T}-\widehat{\mu}_{k}\right)+\right.$ $\left.y_{i k 1}^{2}\right)$

After some manipulations, we get

$\widehat{\sigma}_{u, 0}^{2}=\bar{c}\left(\mathbf{y}_{T}\right)-\widehat{\pi}_{0} \bar{c}\left(\mathbf{y}_{1}, \mathbf{y}_{T}\right)-\frac{1}{\widehat{\pi}_{0}} \bar{c}\left(\mathbf{y}_{1}, \mathbf{y}_{T}\right)+\bar{c}\left(\mathbf{y}_{1}\right)$.

Using $\widehat{\sigma}_{1,0}^{2}-\widehat{\sigma}_{u, 0}^{2}=\widehat{\pi}_{0}^{2} \widehat{\sigma}_{1,0}^{2}=\widehat{\pi}_{0} c\left(\mathbf{y}_{1}, \mathbf{y}_{T}\right)=\frac{1}{\widehat{\pi}_{0}} \bar{c}\left(\mathbf{y}_{1}, \mathbf{y}_{T}\right)-\bar{c}\left(\mathbf{y}_{T}\right)+\widehat{\pi}_{0} \bar{c}\left(\mathbf{y}_{1}, \mathbf{y}_{T}\right)+$ $\frac{1}{\widehat{\pi}_{0}} \bar{c}\left(\mathbf{y}_{1}, \mathbf{y}_{T}\right)-\bar{c}\left(\mathbf{y}_{1}\right)$ or $\frac{2}{\widehat{\pi}_{0}} \bar{c}\left(\mathbf{y}_{1}, \mathbf{y}_{T}\right)-\bar{c}\left(\mathbf{y}_{T}\right)-\bar{c}\left(\mathbf{y}_{1}\right)=0$, we have $\widehat{\pi}_{0}=\frac{2 \bar{c}\left(\mathbf{y}_{1}, \mathbf{y}_{T}\right)}{\bar{c}\left(\mathbf{y}_{T}\right)+\bar{c}\left(\mathbf{y}_{1}\right)}$ and $\widehat{\sigma}_{u, 0}^{2}=\frac{\bar{c}\left(\mathbf{y}_{T}\right)+\bar{c}_{2}\left(\mathbf{y}_{1}\right)}{2}-\frac{2 \bar{c}\left(\mathbf{y}_{1}, \mathbf{y}_{T}\right)^{2}}{\bar{c}\left(\mathbf{y}_{T}\right)+\bar{c}\left(\mathbf{y}_{1}\right)}$ follows.

Now, $\frac{1}{N K} \sum_{k=1}^{K} \sum_{i=1}^{N}\left(y_{i k T}-\widehat{\pi}_{0} y_{i k 1}-\widehat{\mu}_{k, 0}\right)^{2}=\frac{1}{N K} \sum_{k=1}^{K} \sum_{i=1}^{N}\left(y_{i k T}-m_{1}\left(\mathbf{y}_{k T}\right)-\right.$ $\left.\widehat{\pi}_{0}\left(y_{i k 1}-m_{1}\left(\mathbf{y}_{1 k}\right)\right)\right)^{2}=\frac{1}{N K} \sum_{k=1}^{K} \sum_{i=1}^{N}\left[\left(y_{i k T}-m_{1}\left(\mathbf{y}_{k T}\right)\right)^{2}-2 \widehat{\pi}_{0}\left(y_{i k T}-m_{1}\left(\mathbf{y}_{k T}\right)\right)\left(y_{i k 1}-\right.\right.$ $\left.\left.m_{1}\left(\mathbf{y}_{1 k}\right)\right)+\widehat{\pi}_{0}^{2}\left(y_{i k 1}-m_{1}\left(\mathbf{y}_{1 k}\right)\right)^{2}\right]=\bar{c}\left(\mathbf{y}_{T}\right)+\bar{c}\left(\mathbf{y}_{1}\right)-2 \widehat{\pi}_{0} \bar{c}\left(\mathbf{y}_{1}, \mathbf{y}_{T}\right)+\left(\widehat{\pi}_{0}^{2}-\right.$ 1) $\bar{c}\left(\mathbf{y}_{1}\right)=2 \widehat{\sigma}_{u, 0}^{2}-\frac{\widehat{\sigma}_{u, 0}^{2}}{\widehat{\sigma}_{1,0}^{2}} \widehat{\sigma}_{1}^{2}$. Inserting gives $\left.\widehat{S}_{R}=\frac{1}{\widehat{\sigma}_{u, 0}^{2}}\left(2 \widehat{\sigma}_{u, 0}^{2}-\frac{\widehat{\sigma}_{u, 0}^{2}}{\widehat{\sigma}_{1,0}^{2}} \widehat{\sigma}_{1}^{2}\right)+\frac{\widehat{\sigma}_{1}^{2}}{\widehat{\sigma}_{1,0}^{2}}\right)=$ $2+\frac{\widehat{\sigma}_{1}^{2}}{\widehat{\sigma}_{1,0}^{2}}-\frac{\widehat{\sigma}_{1}^{2}}{\widehat{\sigma}_{1,0}^{2}}=2$ and

$$
L_{0}=-\frac{N K}{2}\left(\ln \left(4 \Pi^{2}\right)+\ln \left(\widehat{\sigma}_{1,0}^{2} \widehat{\sigma}_{u, 0}^{2}\right)+2\right)
$$

(iv) Summing up, the LR test is calculated as follows 
1. Calculate $\widehat{\sigma}_{1}^{2}=\bar{c}\left(\mathbf{y}_{1}\right)$ and $\widehat{\sigma}_{u}^{2}=\bar{c}(\mathbf{u})$ for the unrestricted model using the residuals of the $\beta$-convergence regression.

2. For the restricted model, we have $\widehat{\sigma}_{1,0}^{2}=\frac{1}{\widehat{\pi}_{0}} \bar{c}\left(\mathbf{y}_{1}, \mathbf{y}_{T}\right)$ and $\widehat{\sigma}_{u, 0}^{2}=\frac{\bar{c}\left(\mathbf{y}_{T}\right)+\bar{c}_{2}\left(\mathbf{y}_{1}\right)}{2}-$ $\frac{2 \bar{c}\left(\mathbf{y}_{1}, \mathbf{y}_{T}\right)^{2}}{\bar{c}\left(\mathbf{y}_{T}\right)+\bar{c}\left(\mathbf{y}_{1}\right)}$.

3. Therefore, the likelihood ratio test

$$
L R=-2\left(L_{1}-L_{0}\right)=N K \ln \left[\frac{\widehat{\sigma}_{1,0}^{2} \widehat{\sigma}_{u, 0}^{2}}{\widehat{\sigma}_{1}^{2} \widehat{\sigma}_{u}^{2}}\right] .
$$

is asymptotically distributed as $\chi^{2}(1)$. In small samples, we use $N K-$ 2.5 instead of $N K$ (see Morrison, 1976). Note, we have a one-sided test, so the significance levels are doubled to get the critical value.

(v) Table 11 below provides a Monte Carlo simulation to assess the power of the LR-test. We use the following parametrization, which fits our data: $\sigma_{u}^{2}=0.025, \sigma_{1}^{2}=0.085$, so that $\pi_{0}=0.84$. The dummies $\mu_{k 1}$ and $\mu_{k}$ are independent draws from a normal distribution with mean 0 and variance 0.25. The error term $\varepsilon$ is drawn from a normal distribution with mean 0 and variance $\sigma_{u}^{2}$. We replicate the experiment 20000 times and calculate the share of rejections at the 5 percent level of significance. For $\pi=\pi_{0}$, this gives the size of the LR-test, for $\pi \neq \pi_{0}$, we get the power of the LR-test. Table 11 exhibits the power function for different numbers of groups $(K)$ and observations per group $(N)$. The Monte Carlo simulation shows that at $K=2$ the power of the LR-test is reasonable, if $N$ is sufficiently large (which is the case in our application). In addition the test is properly sized. 
Table 1: Country Specific Mean Parities

\begin{tabular}{lrrr}
\hline Country & 1980 & 1990 & 1996 \\
\hline Belgium & -0.33 & -0.26 & -0.24 \\
Denmark & -0.43 & -0.49 & -0.47 \\
France & -0.35 & -0.28 & -0.31 \\
Germany & -0.37 & -0.27 & -0.30 \\
Greece & -0.05 & -0.02 & -0.07 \\
Ireland & -0.23 & -0.19 & -0.18 \\
Italy & -0.06 & -0.30 & -0.16 \\
Luxembourg & -0.28 & -0.24 & -0.27 \\
Netherlands & -0.33 & -0.20 & -0.20 \\
Portugal & 0.06 & 0.11 & -0.03 \\
Spain & -0.09 & -0.23 & -0.12 \\
United Kingdom & -0.31 & -0.14 & -0.10 \\
\hline EU12 & -0.23 & -0.21 & -0.20 \\
\hline Austria & -0.32 & -0.31 & -0.33 \\
Finland & - & -0.62 & -0.36 \\
Iceland & - & -0.48 & -0.31 \\
Norway & -0.47 & -0.54 & -0.44 \\
Sweden & - & -0.53 & -0.46 \\
Switzerland & - & -0.49 & -0.51 \\
\hline EFTA & -0.40 & -0.49 & -0.40 \\
\hline Australia & - & -0.09 & -0.09 \\
Canada & -0.05 & -0.13 & 0.07 \\
Japan & -0.21 & -0.37 & -0.55 \\
New Zealand & -0.23 & -0.01 & -0.13 \\
Turkey & -0.33 & 0.43 \\
\hline Rest of OECD & -0.06 & -0.05 \\
All Countries & -0.25 & -0.22 \\
\hline Note: Tab & - & & \\
\hline
\end{tabular}

Note: Table 1 shows mean purchasing power parities over all goods (basic headings) for each country and country groups. 
Table 2: Sigma Convergence - 1980 to 1990

\begin{tabular}{|c|c|c|c|c|}
\hline & $\Delta \sigma_{n t r}$ & $L R_{n t r}$ & $\Delta \sigma_{t r}$ & $L R_{t r}$ \\
\hline Belgium & -0.11 & 0.87 & 0.04 & 0.20 \\
\hline Denmark & -0.14 & 1.05 & 0.05 & 0.24 \\
\hline France & -0.04 & 0.09 & 0.03 & 0.13 \\
\hline Germany & -0.33 & $8.34^{* *}$ & -0.06 & 0.51 \\
\hline Greece & -0.06 & 0.20 & 0.02 & 0.03 \\
\hline Ireland & -0.35 & $9.96^{* *}$ & -0.02 & 0.03 \\
\hline Italy & -0.23 & $3.27 *$ & 0.09 & 1.04 \\
\hline Luxembourg & -0.17 & 1.96 & -0.08 & 0.94 \\
\hline Netherlands & -0.22 & $3.15^{*}$ & -0.05 & 0.28 \\
\hline Portugal & -0.16 & 1.54 & -0.06 & 0.64 \\
\hline Spain & -0.06 & 0.20 & -0.01 & 0.03 \\
\hline United Kingdom & -0.00 & 0.00 & 0.08 & 0.71 \\
\hline EU12 & -0.18 & $22.18^{* *}$ & 0.00 & 0.01 \\
\hline Austria & -0.20 & 2.58 & -0.05 & 0.28 \\
\hline Norway & -0.34 & $8.12^{* *}$ & 0.02 & 0.07 \\
\hline EFTA & -0.27 & $10.57^{* *}$ & 0.03 & 0.02 \\
\hline Japan & -0.05 & 0.13 & 0.10 & 1.20 \\
\hline Canada & 1.21 & $24.41^{* *}$ & 0.59 & $25.25^{* *}$ \\
\hline Rest of OECD & 0.08 & 0.48 & 0.13 & $7.04^{* *}$ \\
\hline All Countries & -0.17 & $27.68^{* *}$ & 0.01 & 0.51 \\
\hline
\end{tabular}

Note: ${ }^{* *}$ significant at $5 \% ;{ }^{*}$ significant at $10 \%$. 
Table 3: Sigma Convergence - 1990 to 1996

\begin{tabular}{|c|c|c|c|c|}
\hline & $\Delta \sigma_{n t r}$ & $L R_{n t r}$ & $\Delta \sigma_{t r}$ & $L R_{t r}$ \\
\hline Belgium & -0.06 & 0.29 & -0.16 & $4.69^{* *}$ \\
\hline Denmark & -0.01 & 0.01 & -0.06 & 0.63 \\
\hline France & -0.02 & 0.05 & -0.20 & $7.58^{* *}$ \\
\hline Germany & 0.09 & 0.54 & -0.12 & 2.46 \\
\hline Greece & 0.22 & $2.93^{*}$ & -0.10 & 2.06 \\
\hline Ireland & -0.17 & 2.24 & -0.10 & 1.80 \\
\hline Italy & 0.02 & 0.03 & -0.22 & $9.81^{* *}$ \\
\hline Luxembourg & -0.12 & 1.17 & -0.09 & 1.47 \\
\hline Netherlands & -0.03 & 0.08 & -0.11 & 1.85 \\
\hline Portugal & -0.03 & 0.11 & -0.20 & $8.93^{* *}$ \\
\hline Spain & -0.06 & 0.27 & -0.20 & $8.30^{* *}$ \\
\hline United Kingdom & -0.12 & 1.44 & -0.20 & $6.62^{* *}$ \\
\hline EU12 & -0.05 & 0.82 & -0.15 & $51.29^{* *}$ \\
\hline Austria & -0.13 & 1.61 & -0.11 & 2.14 \\
\hline Finland & 0.00 & 0.00 & -0.14 & $3.33^{*}$ \\
\hline Iceland & 0.12 & 0.82 & 0.00 & 0.00 \\
\hline Norway & -0.09 & 0.69 & -0.12 & 2.70 \\
\hline Sweden & -0.04 & 0.10 & -0.20 & $7.48^{* *}$ \\
\hline Switzerland & 0.11 & 0.78 & -0.13 & $2.95^{*}$ \\
\hline EFTA & 0.02 & 0.03 & -0.13 & $14.34^{* *}$ \\
\hline Australia & 0.32 & $4.65^{* *}$ & 0.11 & 1.69 \\
\hline Canada & 0.24 & $3.17^{*}$ & 0.17 & $3.38^{*}$ \\
\hline Japan & -0.02 & 0.04 & -0.02 & 0.10 \\
\hline Turkey & -0.01 & 0.01 & -0.28 & $18.40^{* *}$ \\
\hline New Zealand & -0.02 & 0.04 & -0.01 & 0.00 \\
\hline Rest of OECD & 0.04 & 0.57 & 0.04 & $4.20^{* *}$ \\
\hline All Countries & -0.02 & 0.08 & -0.11 & $61.29^{* *}$ \\
\hline
\end{tabular}

Note: ${ }^{* *}$ significant at $5 \% ;{ }^{*}$ significant at $10 \%$. 
Table 4: Sigma Convergence - 1980 to 1996

\begin{tabular}{|c|c|c|c|c|}
\hline & $\Delta \sigma_{n t r}$ & $L R_{n t r}$ & $\Delta \sigma_{t r}$ & $L R_{t r}$ \\
\hline Belgium & -0.16 & 1.74 & -0.12 & 1.92 \\
\hline Denmark & -0.14 & 1.32 & -0.03 & 0.11 \\
\hline France & -0.11 & 0.60 & -0.16 & $3.81 *$ \\
\hline Germany & -0.26 & $4.59^{* *}$ & -0.18 & $4.90^{* *}$ \\
\hline Greece & 0.14 & 1.12 & -0.07 & 0.63 \\
\hline Ireland & -0.46 & $18.16^{* *}$ & -0.13 & 2.25 \\
\hline Italy & -0.20 & 2.66 & -0.15 & $3.30 *$ \\
\hline Luxembourg & -0.27 & $4.66^{* *}$ & -0.16 & $3.94^{* *}$ \\
\hline Netherlands & -0.24 & $3.86^{* *}$ & -0.16 & $3.58^{*}$ \\
\hline Portugal & -0.21 & $2.84 *$ & -0.24 & $9.96^{* *}$ \\
\hline Spain & -0.11 & 0.80 & -0.20 & $6.54^{* *}$ \\
\hline United Kingdom & -0.09 & 0.46 & -0.14 & $2.88^{*}$ \\
\hline EU12 & -0.22 & $29.57^{* *}$ & -0.15 & $39.99^{* *}$ \\
\hline Austria & -0.33 & $7.93^{* *}$ & -0.16 & $3.61 *$ \\
\hline Norway & -0.40 & $12.76^{* *}$ & -0.13 & 2.55 \\
\hline EFTA & -0.38 & $21.46^{* *}$ & -0.13 & $6.12^{* *}$ \\
\hline Japan & -0.07 & 0.27 & 0.05 & 0.29 \\
\hline Canada & 1.89 & $42.52^{* *}$ & 0.90 & $47.33^{* *}$ \\
\hline Rest of OECD & 0.26 & 1.75 & 0.36 & $8.58^{* *}$ \\
\hline All Countries & -0.19 & $36.37^{* *}$ & -0.08 & $27.13^{* *}$ \\
\hline
\end{tabular}

Note: ${ }^{* *}$ significant at $5 \% ;{ }^{*}$ significant at $10 \%$. 


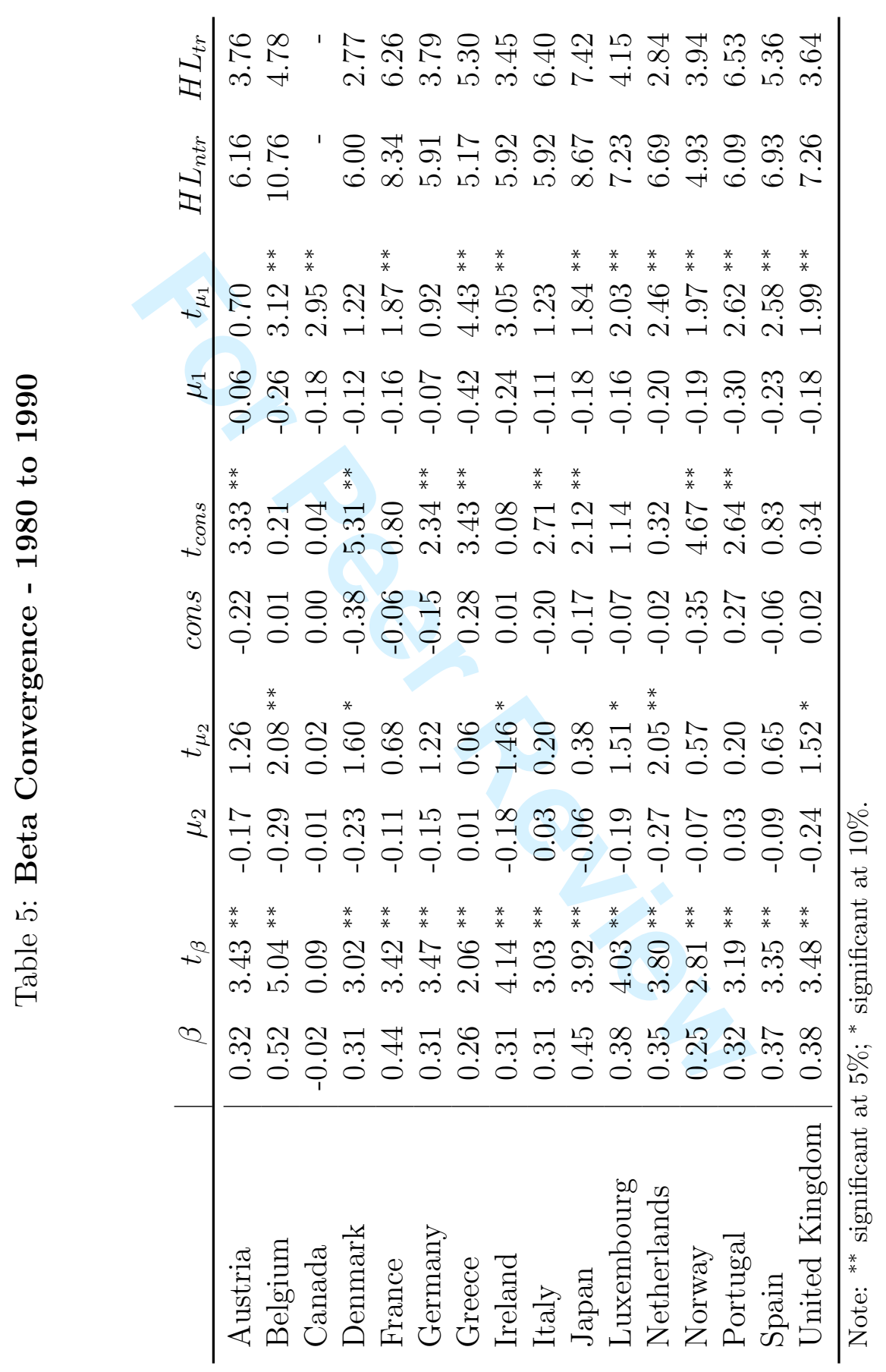




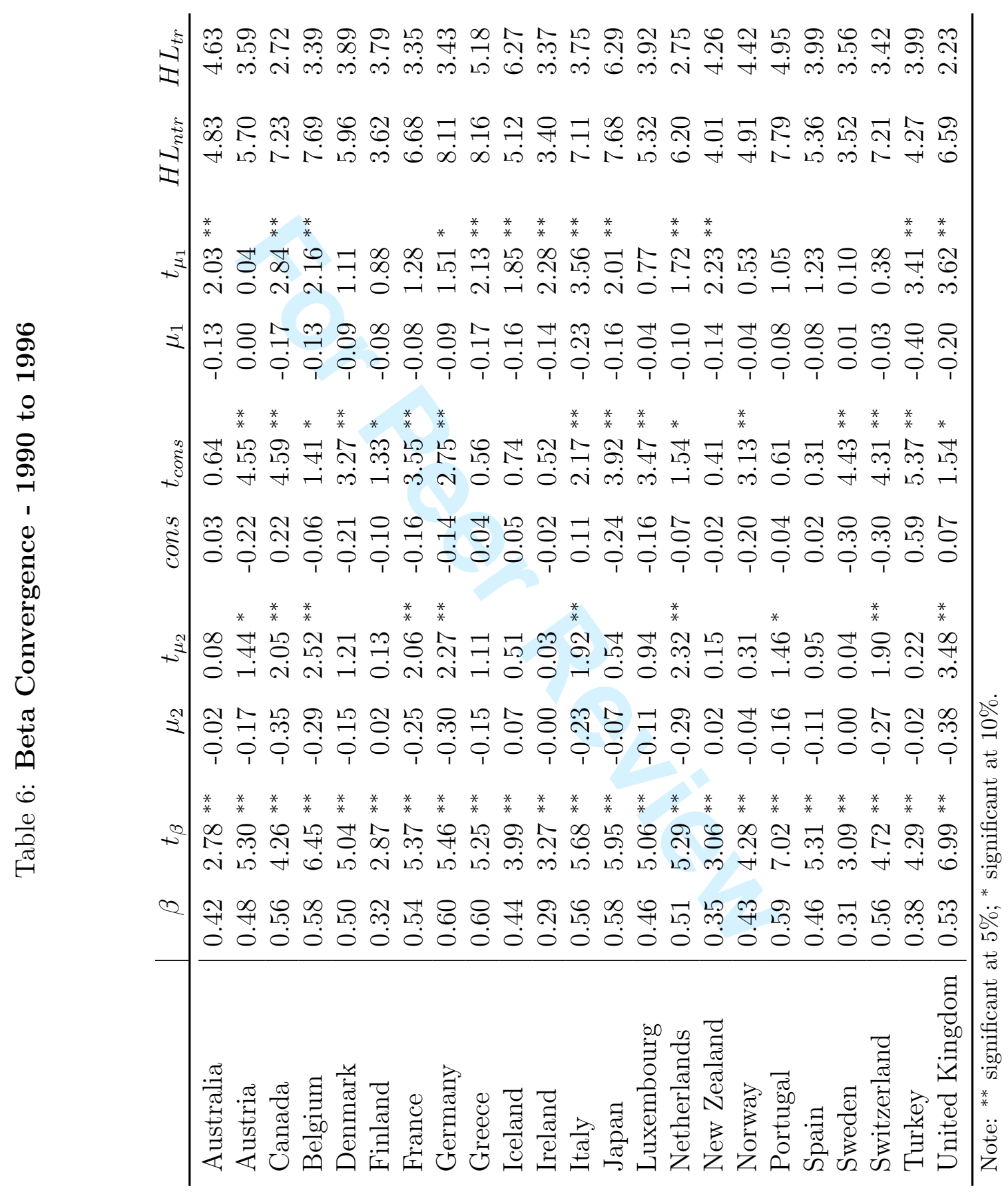




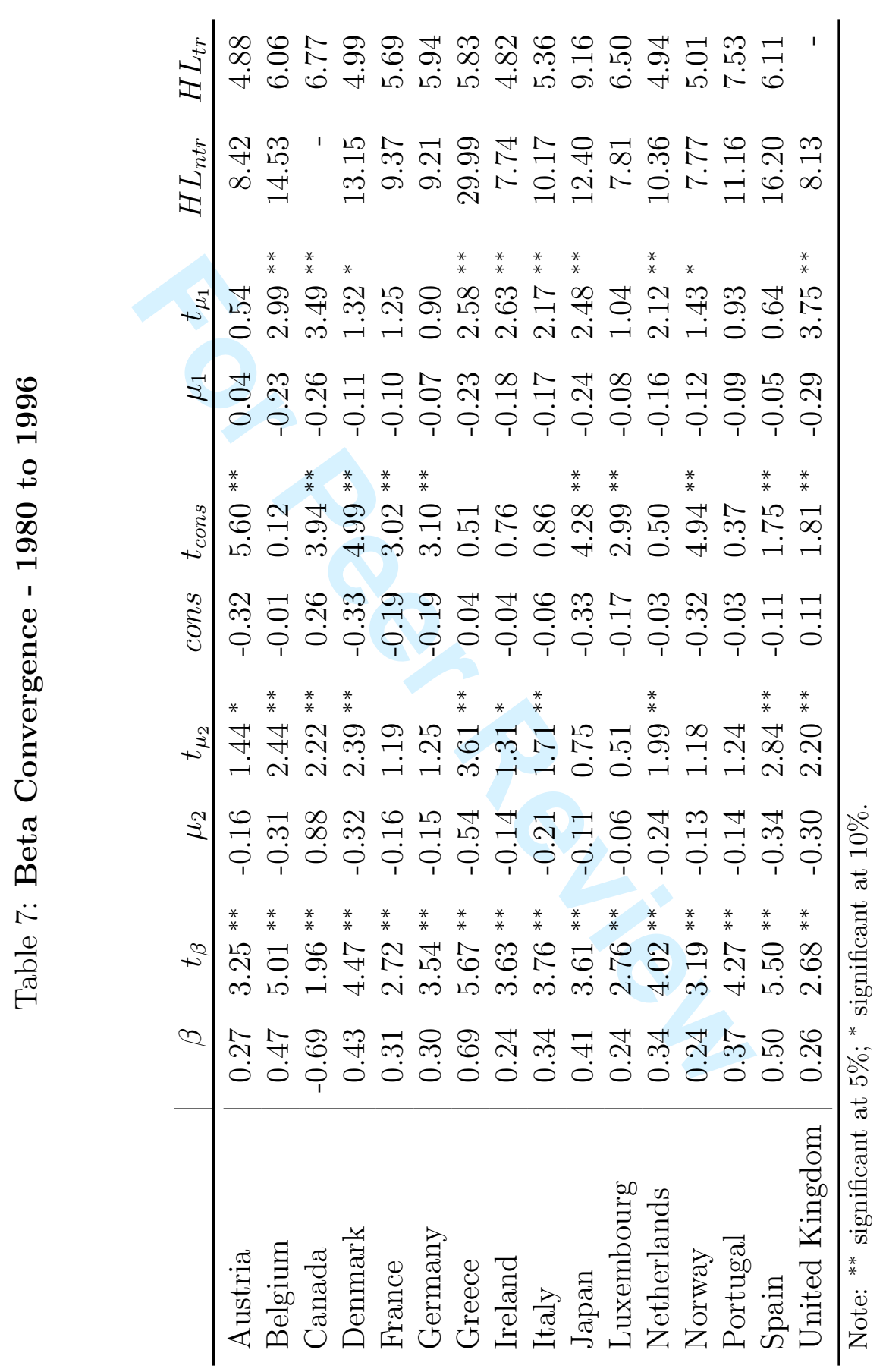




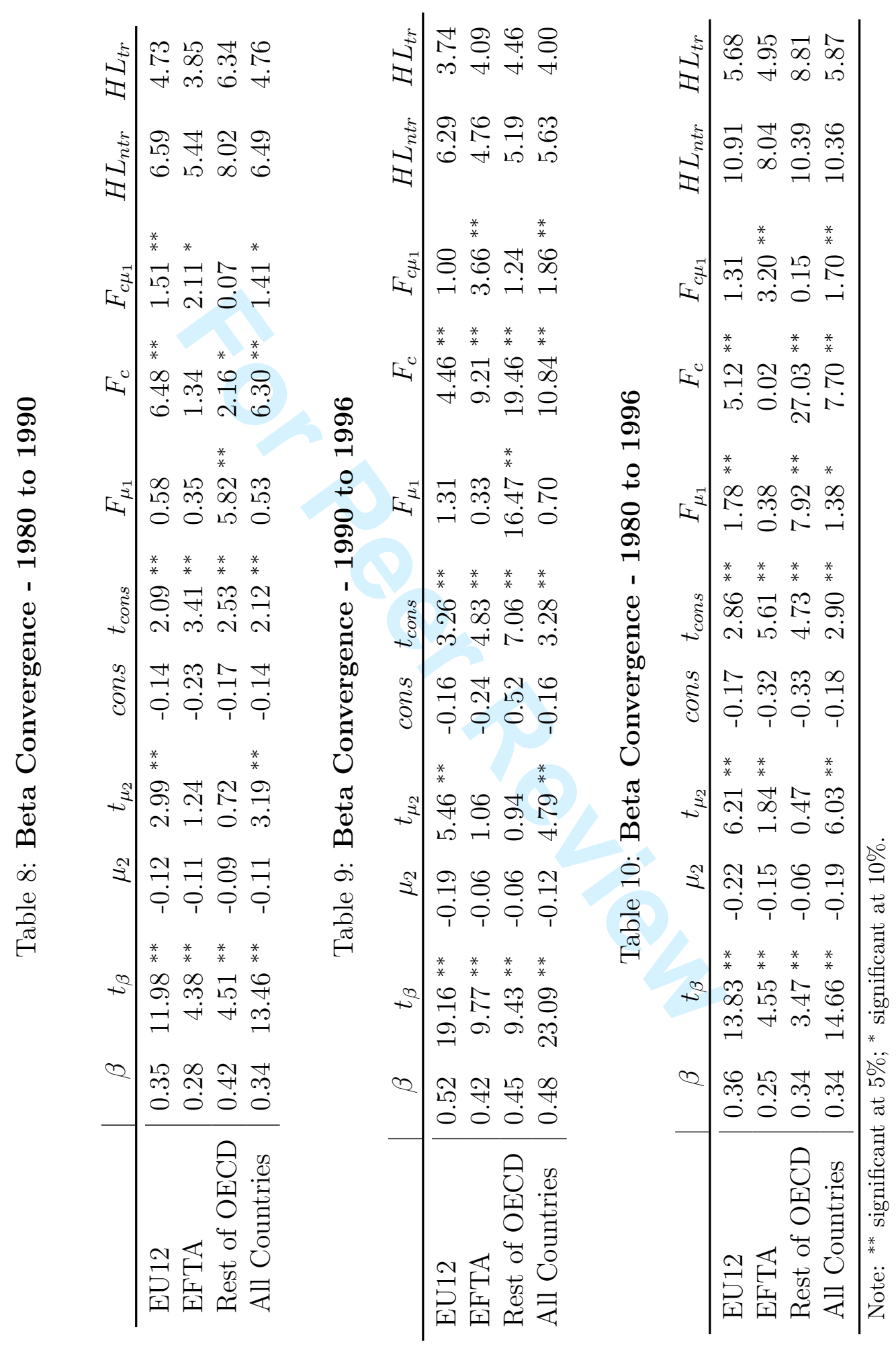




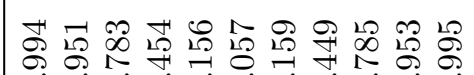

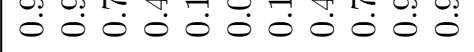

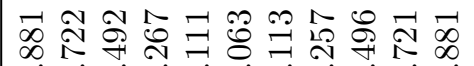
它

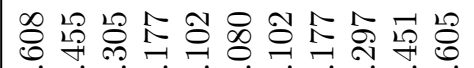

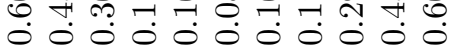

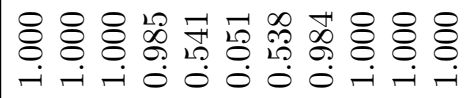
\& \& -i

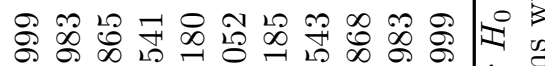

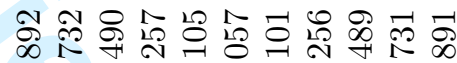

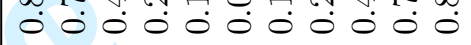

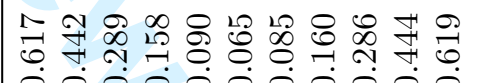
$\because 0000000000$ $\infty$ 눙 ○

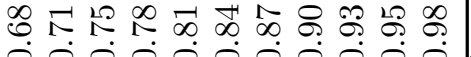
00000000000

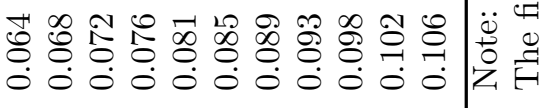




\section{References}

Anderson, T.W. and C. Hsiao, "Formulation and Estimation of Dynamic Models Using Panel Data," Journal of Econometrics, 1982, 18, 47-82.

Barro, R.J. and X. Sala i Martin, Economic Growth, MIT Press, 2003.

Baum, C.F., J.T. Barkoulas, and M. Caglayan, "Nonlinear Adjustment to Purchasing Power Parity in the Post-Bretton Woods Era," Journal of International Money and Finance, 2001, 20, 379-399.

Bergstrand, J.H., "Structural Determinants of Real Exchange Rates and National Price Levels," American Economic Review, 1991, 81, 325-334.

_ , "Real Exchange Rates, National Price Levels, and the Peace Dividend," American Economic Review: Papers and Proceedings, 1992, 82, 55-61.

Cannon, E.S. and N.W. Duck, "Galton's Fallacy and Economic Convergence," Oxford Economic Papers, 2000, 52, 415-419.

Carree, M.A. and L. Klomp, "Testing the Convergence Hypothesis: A Comment," Review of Economics and Statistics, 1997, 79, 683-686.

Cecchetti, S.G., N.C. Mark, and R.J. Sonora, "Price Level Convergence Among United States Cities: Lessons for the European Central Bank," NBER Working Paper, 2000, 7681.

Cheung, Y.W. and K.S. Lai, "On the Purchasing Power Parity Puzzle," Journal of International Economics, 2000 a, 52, 321-330. 
and __ , "On Cross-Countries Differences in the Persistence of Real Exchange Rates," Journal of International Economics, 2000 b, 50, 375397.

Crownover, C., J. Pippenger, and D.G. Steigerwald, "Testing for Absolute Purchasing Power Parity," Journal of International Money and Finance, 1996, 15, 783-796.

Crucini, M.J. and M. Shintani, "Persistence in Law-of-One-Price Deviations: Evidence from Micro-data," 2004. Working Paper No. 02-W22R, Vanderbilt University.

C.I. Telmer, and M. Zachariadis, "Dispersion in Real Exchange Rates," 2000. Working Paper No. 00-W13, Vanderbilt University.

__ _ _ and __ , "Understanding European Real Exchange Rates," 2001. Working Paper No. 01-W20, Vanderbilt University. , and __ , "Understanding European Real Exchange Rates," American Economic Review, 2005, 95 (3), 724-738.

Cumby, R., "Forecasting Exchange Rates and Relative Prices with the Hamburger Standard: Is what you want what you get with McParity?," NBER Working Paper, 1996, 5675.

Drechsler, L., "Weighting of Index Numbers in International Comparisons," Review of Income and Wealth, 1973.

Egger, P. and M. Pfaffermayr, "On Testing Conditional SigmaConvergence," 2006. Working Paper, University of Innsbruck. 
Engel, C. and J. Rogers, "How wide is the Border?," American Economic Review, 1996, 86, 1112-1125.

Froot, K.A., M. Kim, and K. Rogoff, "The Law of One Price over 700 Years," International Monetary Fund Working Paper, 2001, $W P / 01 / 174$.

Fuller, W.A. and G.E. Battese, "Transformations for Estimation of Linear Models with Nested-Error Structure," Journal of the American Statistical Association, 1973, 68, 626-632.

Gilbert, M. and I.B. Kravis, "An International Comparison of National Products and the Purchasing Power of Currencies: A Study of the United States, The United Kingdom, France, Germany and Italy," OEEC, Paris, 1954.

Giovannini, A., "Exchange Rates and Traded Goods Prices," Journal of International Economics, 1988, 24, 45-68.

Goldberg, P.K. and F. Verboven, "Market Integration and Convergence to the Law of One Price: Evidence from the European Car Market," Journal of International Economics, 2005, 65, 49-73.

Gosh, A.R. and H.C. Wolf, "Pricing in International Markets: Lessons from the Economist," NBER Working Paper, 1994, 4806.

Hart, P., "Galtonian Regression across Countries and the Convergence of Productivity," Oxford Bulletin of Economics and Statistics, 1995, 57, $287-293$. 
Haskel, J. and H.C. Wolf, "The Law of One Price - A Case Study," Scandinavian Journal of Economics, 2001, 103, 545-558.

Heston, A. and R. Summers, "The Penn World Table (Mark 5): An Expanded Set of International Comparisons, 1950-1988," Quarterly Journal of Economics, 1991, 106 (2), 327-368.

Higgins, M. and E. Zakrajsek, "Purchasing Power Parity: Three Stakes Through the Heart of the Unit Root Null," Board of Governors of the Federal Reserve System, 2000, 22.

Hsiao, C., Analysis of Panel Data, 2 ed., Cambridge University Press, 2003.

Isard, P., "How far can we push the Law of One Price?," American Economic Review, 1977, 67, 942-948.

Knetter, M., "Price Discrimination by US and German Exporters," American Economic Review, 1989, 79, 198-210.

, "International Comparison of Pricing to Market Behavior," American Economic Review, 1993, 83, 473-486.

Kravis, I.B., A. Heston, and R. Summers, United Nations International Comparison Programme, John Hopkins University Press, 1978.

$\ldots$ _ _ , and _ _ World Product and Income, International Comparisons of Real Gross Product, John Hopkins University Press, 1982.

Lutz, M., "Pricing in Segmented Markets, Abritrage Barriers and the Law of One Price: Evidence from the European Car Market," 2001. Unpublished paper, University of St. Gallen. 
"Beyond Burgernomics and MacParity: Exchange Rate Forecasts Based on the Law of One Price," 2002. Unpublished paper, University of St. Gallen.

Morrison, D.F., Multivariate Statistical Methods, McGraw-Hill, 1976.

Murray, C.J. and D.H. Papell, "The Purchasing Power Parity Persistence Paradigm," Journal of International Economics, 2002, 56, 1-19.

Obstfeld, M. and K. Rogoff, Foundations of International Macroeconomics, MIT Press, 1996.

O’Connell, P.G.J., "The Overvaluation of Purchasing Power Parity," Journal of International Finance, 1998 a, 44, 1-19.

__ , "Market Frictions and Real Exchange Rates," Journal of International Money and Finance, 1998 b, 17, 71-95.

and S.J. Wei, "The bigger they are, the harder they fall: Retail Price Differences across U.S. Cities," Journal of International Finance, 2002, $56,21-53$.

Parsley, D. and S.J. Wei, "A Prism into the PPP Puzzles: The MicroFoundations of Big Mac Real Exchange Rates," CEPR Working Paper, 2004.

Parsley, D.C. and S.J. Wei, "Convergence to the Law of One Price Without Trade Barriers or Currency Fluctuations," Quarterly Journal of Economics, 1996, 111, 1211-1236. 
and __ , "Explaining the Border Effect: The Role of Exchange Rate Variability, Shipping Costs and Geography," Journal of Intenational Economics, 2001, 55 (1), 87-105.

Rogers, J., "Price Level Convergence, Relative Prices, and Inflation in Europe," Federal Reserve Board International Finance Discussion Paper, $2001,699$.

Rogoff, K., "The Purchasing Power Parity Puzzle," Journal of Economic Literature, 1996, 34, 647-668.

Taylor, A.M., "Potential Pitfalls for the Purchasing Power Parity Puzzle? Sampling and Specification Biases in Mean-Reversion Tests of the Law of One Price," Econometrica, 2001, 69, 473-498.

, "A Century of Purchasing Power Parity," Review of Economics and Statistics, 2002, 84, 139-150.

and M. P. Taylor, "The Purchasing Power Parity Debate," Journal of Economic Perspectives, 2004, 18 (4), 135-158.

Taylor, M.P. and D.A. Peel, "Nonlinear Adjustment, Long-Run Equilibrium and Exchange Rate Fundamentals," Journal of International Money and Finance, 2000, 19, 33-53.

United-Nations, Handbook of the International Comparison Programme number F 62. In 'Studies in Methods.', United-Nations, 1992. 